University of Montana

ScholarWorks at University of Montana

Ecosystem and Conservation Sciences Faculty

Publications

Ecosystem and Conservation Sciences

2010

\title{
Experimental Drought in a Tropical Rain Forest Increases Soil Carbon Dioxide Losses to the Atmosphere
}

Cory C. Cleveland

The University of Montana, cory.cleveland@umontana.edu

William R. Wieder

Sasha C. Reed

Alan R. Townsend

Follow this and additional works at: https://scholarworks.umt.edu/decs_pubs

Part of the Ecology and Evolutionary Biology Commons

Let us know how access to this document benefits you.

\section{Recommended Citation}

Cleveland, Cory C.; Wieder, William R.; Reed, Sasha C.; and Townsend, Alan R., "Experimental Drought in a Tropical Rain Forest Increases Soil Carbon Dioxide Losses to the Atmosphere" (2010). Ecosystem and Conservation Sciences Faculty Publications. 16.

https://scholarworks.umt.edu/decs_pubs/16

This Article is brought to you for free and open access by the Ecosystem and Conservation Sciences at ScholarWorks at University of Montana. It has been accepted for inclusion in Ecosystem and Conservation Sciences Faculty Publications by an authorized administrator of ScholarWorks at University of Montana. For more information, please contact scholarworks@mso.umt.edu. 


\title{
Experimental drought in a tropical rain forest increases soil carbon dioxide losses to the atmosphere
}

\author{
Cory C. Cleveland, ${ }^{1,4}$ William R. Wieder,${ }^{2}$ Sasha C. Reed, ${ }^{1,3}$ and Alan R. Townsend ${ }^{2}$ \\ ${ }^{1}$ Department of Ecosystem and Conservation Sciences, University of Montana, 32 Campus Drive/CHCB 423B, \\ Missoula, Montana 59812 USA \\ ${ }^{2}$ Department of Ecology and Evolutionary Biology and the Institute of Arctic and Alpine Research, University of Colorado, \\ Boulder, Colorado 80303 USA \\ ${ }^{3}$ U.S. Geological Survey, Southwest Biological Science Center, Moab, Utah 84532 USA
}

\begin{abstract}
Climate models predict precipitation changes for much of the humid tropics, yet few studies have investigated the potential consequences of drought on soil carbon (C) cycling in this important biome. In wet tropical forests, drought could stimulate soil respiration via overall reductions in soil anoxia, but previous research suggests that litter decomposition is positively correlated with high rainfall fluxes that move large quantities of dissolved organic matter (DOM) from the litter layer to the soil surface. Thus, reduced rainfall could also limit $\mathrm{C}$ delivery to the soil surface, reducing respiration rates. We conducted a throughfall manipulation experiment to investigate how $25 \%$ and $50 \%$ reductions in rainfall altered both $\mathrm{C}$ movement into soils and the effects of those DOM fluxes on soil respiration rates. In response to the experimental drought, soil respiration rates increased in both the $-25 \%$ and $-50 \%$ treatments. Throughfall fluxes were reduced by $26 \%$ and $55 \%$ in the $-25 \%$ and $-50 \%$ treatments, respectively. However, total DOM fluxes leached from the litter did not vary between treatments, because the concentrations of leached DOM reaching the soil surface increased in response to the simulated drought. Annual DOM concentrations averaged $7.7 \pm 0.8,11.2 \pm 0.9$, and $15.8 \pm 1.2 \mathrm{mg} \mathrm{C} / \mathrm{L}$ in the control, $-25 \%$, and $-50 \%$ plots, respectively, and DOM concentrations were positively correlated with soil respiration rates. A laboratory incubation experiment confirmed the potential importance of DOM concentration on soil respiration rates, suggesting that this mechanism could contribute to the increase in $\mathrm{CO}_{2}$ fluxes observed in the reduced rainfall plots. Across all plots, the data suggested that soil $\mathrm{CO}_{2}$ fluxes were partially regulated by the magnitude and concentration of soluble $\mathrm{C}$ delivered to the soil, but also by soil moisture and soil oxygen availability. Together, our data suggest that declines in precipitation in tropical rain forests could drive higher $\mathrm{CO}_{2}$ fluxes to the atmosphere both via increased soil $\mathrm{O}_{2}$ availability and through responses to elevated DOM concentrations.
\end{abstract}

Key words: carbon cycle; climate change; experimental drought; Golfo Dulce Forest Reserve, Costa Rica; soil respiration; tropical rain forest.

\section{INTRODUCTION}

Tropical forests play a critical role in the global carbon (C) cycle. They store $\sim 25 \%$ of global terrestrial organic $\mathrm{C}$ in their biomass and soil (e.g., Schlesinger 1997, Jobbagy and Jackson 2000, Tarnocai et al. 2009), they account for roughly $35 \%$ of terrestrial net primary productivity (NPP), and they exchange more $\mathrm{C}$ with the atmosphere annually than any other biome (Phillips et al. 1998, Grace et al. 2001). Given these sizable C pools and fluxes, even small changes in $\mathrm{C}$ exchange between tropical forests and the atmosphere could have important consequences for the global $\mathrm{C}$ budget, atmospheric composition, and climate.

Manuscript received 29 August 2009; revised 3 December 2009; accepted 7 December 2009. Corresponding Editor: H. A. L. Henry.

${ }^{4}$ E-mail: Cory.Cleveland@umontana.edu
The large pools and active fluxes that characterize the $\mathrm{C}$ cycle in many tropical forests are sustained by a climate that is nearly optimal for plant growth; consistently warm temperatures and ample rainfall fuel some of the highest $\mathrm{C}$ uptake rates on earth (Phillips et al. 1998, Grace et al. 2001). However, the same climatic conditions that combine to maximize productivity also promote high $\mathrm{C}$ losses via soil respiration (Raich and Schlesinger 1992), and climate change could alter the balance between C inputs (via NPP) and losses (via decomposition and soil respiration) (Rustad et al. 2000, Forster et al. 2007). The potential effects of climate change on the $\mathrm{C}$ cycle in tropical forests remain poorly understood, but recent research indicates that they could be profound. For example, Forster et al. (2007) found a significant negative relationship between tree growth and mean annual daily minimum temperature, suggesting that temperature increases in tropical latitudes predicted by many global climate models (IPCC 2007) 
could lead to declines in NPP. Declines in plant C uptake, combined with predicted increases in tropical soil respiration $\mathrm{C}$ losses with warming (Townsend et al. 1992, Trumbore 1997, Davidson and Janssens 2006), have the potential to significantly alter net $\mathrm{C}$ storage in tropical forests.

In all likelihood, climate change will also alter the patterns, magnitude, and intensity of precipitation in the tropics in ways that may affect the $\mathrm{C}$ cycle (Neelin et al. 2006, Malhi et al. 2008). The current generation of global climate models is much less skilled at predicting future precipitation than temperature (IPCC 2007), but a number of changes seem likely. Models predict: (1) decreases in precipitation along the margins of convection zones; (2) decreases in precipitation across much of the Amazon Basin; and (3) decreases in precipitation in the Caribbean and Central American region (Cox et al. 2004, Neelin et al. 2006, Malhi et al. 2008). Unfortunately, while decreases in precipitation are predicted for much of the humid tropics, our understanding of how reductions in rainfall will alter tropical $\mathrm{C}$ cycling remains poor (but see Davidson et al. 2004, 2008). This is especially true for the wettest portion of the biome.

In theory, reduced rainfall in tropical forests could have either positive or negative effects on soil respiration. The direct relationship between soil respiration and mean annual precipitation (Raich and Schlesinger 1992) suggests that rates may decrease in response to lower rainfall. For example, lower rainfall in relatively dry sites could drive increases in plant root mortality, declines in decomposer activity (or both), and hence lower soil $\mathrm{CO}_{2}$ emissions (e.g., Sotta et al. 2007). Alternatively, increased decomposition of dead roots may more than offset root mortality-related declines in soil respiration, thereby driving higher $\mathrm{CO}_{2}$ losses to the atmosphere, at least in the short term. Two previous throughfall manipulation experiments conducted in relatively dry sites in the Brazilian Amazon had different results: One showed that reductions in rainfall did affect the production of some trace gases, but they had no significant effect on soil $\mathrm{CO}_{2}$ losses (Davidson et al. 2004, 2008); another showed declines in soil $\mathrm{CO}_{2}$ in response to experimental drought (Sotta et al. 2007).

However, virtually nothing is known about the potential effects of declining rainfall in tropical forests occupying the wet end of the precipitation spectrum. In such sites (i.e., those receiving $>2500 \mathrm{~mm} / \mathrm{yr}$ ), reductions in precipitation could conceivably have either positive or negative effects on soil respiration. First, drying in wet sites could increase soil respiration by enhancing oxygen $\left(\mathrm{O}_{2}\right)$ diffusion, thereby stimulating rates of aerobic decomposition and nutrient cycling (Silver et al. 1999, Schuur 2001, Schuur and Matson 2001). However, previous research in Costa Rican sites suggested that high rainfall promotes rapid rates of decomposition and high soil $\mathrm{CO}_{2}$ fluxes by delivering large amounts of readily decomposable soluble $\mathrm{C}$ from the litter layer to the soil surface (Cleveland et al. 2006,
Wieder et al. 2009). These results imply that decreases in precipitation could reduce $\mathrm{CO}_{2}$ fluxes to the atmosphere, even in extremely wet tropical forests.

We hypothesized that reductions in rainfall (throughfall) would reduce fluxes of dissolved organic matter (DOM) through the litter layer and that reductions of labile $\mathrm{C}$ delivered to the soil surface would lead to declines in soil respiration. To address these hypotheses, we conducted a throughfall manipulation experiment in a wet tropical forest site on the Osa Peninsula in southwestern Costa Rica. Our objective was to experimentally manipulate the amount of throughfall reaching the litter layer and hence the amount of DOM delivered to the soil surface. Our goal was not to manipulate soil moisture per se, but to isolate the linkages between rainfall, DOM leaching, and soil $\mathrm{CO}_{2}$ fluxes.

\section{Methods \\ Study site}

The experiment was conducted in a diverse lowland tropical rain forest on the Osa peninsula in the Golfo Dulce Forest Reserve $\left(8^{\circ} 43^{\prime} \mathrm{N}, 83^{\circ} 37^{\prime} \mathrm{W}\right)$, southwest Costa Rica. Average annual temperature is $\sim 26.5^{\circ} \mathrm{C}$ and annual rainfall averages $>5000 \mathrm{~mm} / \mathrm{yr}$, but the site experiences a dry season between December and April when rainfall is typically $<100 \mathrm{~mm} /$ month. Litterfall and standing litter mass reach annual maxima during the dry season (Cleveland and Townsend 2006), and soil respiration increases to an annual maximum during the early rainy season (e.g., May; Cleveland et al. 2006). Soil at the site is classified as an Ultisol that developed on a steeply dissected landscape in the Osa basaltic complex (Berrange and Thorpe 1988). A complete site description including soil physical and chemical characteristics can be found in Cleveland et al. (2006).

\section{Experimental design}

We constructed a set of $2.4 \times 2.4 \mathrm{~m}$ throughfall exclosures to manipulate precipitation and impose a 12month experimental drought (see Plate 1). For each exclosure, 5-cm diameter PVC pipes were cut in half lengthwise and mounted on an aluminum frame $\sim 1 \mathrm{~m}$ above the soil surface. The PVC pipes acted as partial rain sheds, preventing the experimental plots from receiving full incoming throughfall, but also allowing ambient light to penetrate to the forest floor and air to circulate freely. The rain-shedding PVC pipes were mounted at either $5 \mathrm{~cm}$ or $15 \mathrm{~cm}$ (on center) intervals to achieve $-50 \%$ or $-25 \%$ reductions in total throughfall, but the exclosures were otherwise open to the atmosphere on both the sides and the top to allow airflow and exchange and prevent temperature differentials. Twenty randomly assigned plots received either $-50 \%$ or $-25 \%$ throughfall treatments $(N=10$ per treatment); an additional 10 plots served as experimental controls. Exclosures were kept in place for the duration 


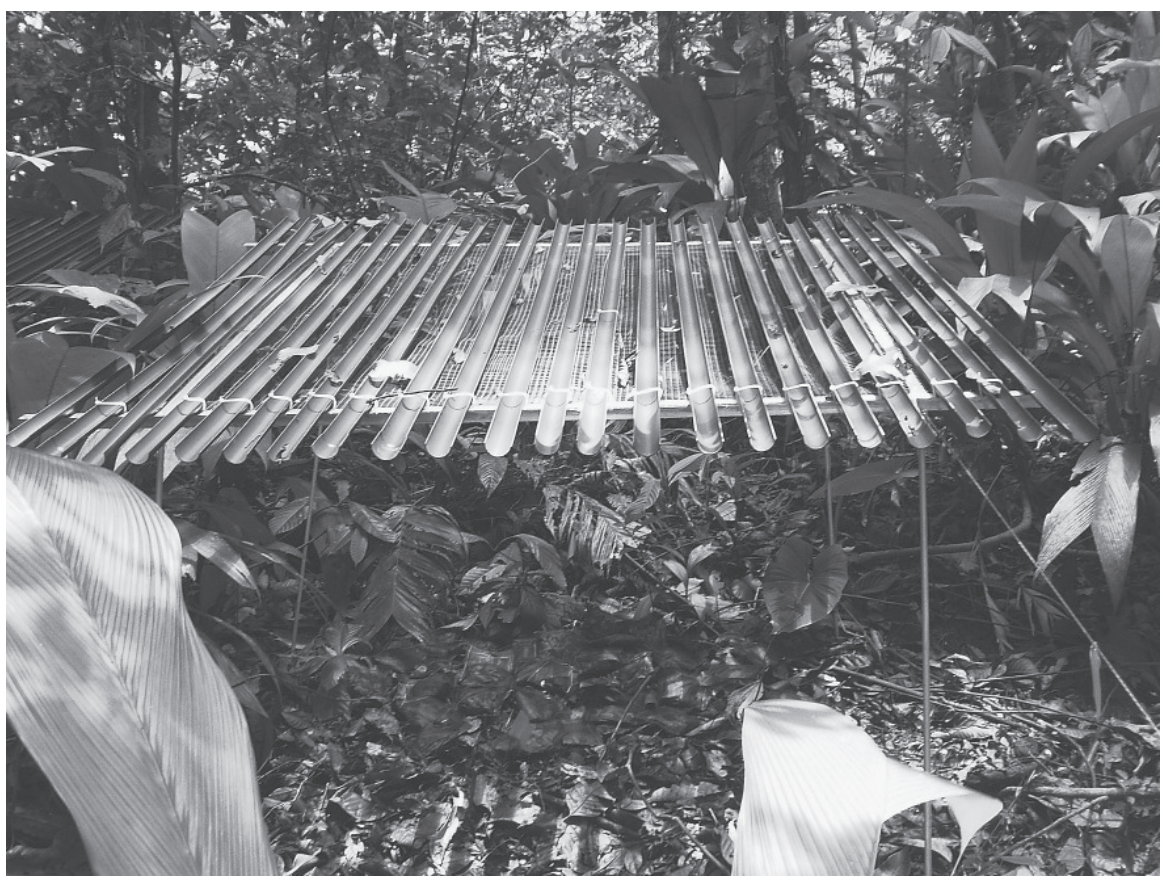

Plate 1. An example of the exclosures constructed to manipulate throughfall and to impose the experimental drought. Photo credit: W. R. Wieder

of the experiment, thus simulating a 12-month decrease in precipitation intensity.

The overall objective of the experiment was to investigate the effects of changing precipitation on DOM delivery and soil respiration (and not on the effects of decreased rainfall on soil moisture per se), thus plots were not trenched (e.g., Davidson et al. 2004). This design ensured that the throughfall manipulation would be concentrated on the litter-soil interface and minimized possible disturbance (via trenching) that could affect soil C cycling (Ngao et al. 2007). Soil moisture and temperature in the plots were measured using an array of HOBO sensors deployed in the plots (Microdaq, Contoocook, New Hampshire, USA), and precipitation was measured using a $\mathrm{HOBO}$ data logging rain gauge placed in a clearing $\sim 400 \mathrm{~m}$ from the study plots. The exclosures used in the present study were permanently deployed in September 2007.

The exclosure design included a $1-\mathrm{cm}$ wire mesh immediately beneath the exclosure gutters, effectively excluding all litterfall from reaching the forest floor. Therefore, a constant amount of litter (based on the average standing litter mass $\left[750 \mathrm{~g}\right.$ litter $\left./ \mathrm{m}^{2}\right]$ at the beginning of the experiment) was added to each plot by pooling litter and dividing equally among plots. At monthly intervals, litter from an adjacent set of parallel $2.4 \mathrm{~m} \times 2.4 \mathrm{~m}$ plots was weighed, divided into 20 equal portions (by mass) and placed under each of the exclosures to normalize monthly litter inputs. This strategy had two purposes: first, to minimize experimental artifacts imposed by the exclosures on litterfall; and second, to standardize the amount of litter in the experimental plots, thereby minimizing the chance that treatment responses were driven by factors other than throughfall.

\section{Litter layer throughfall and DOM fluxes}

To measure the volume of water passing through the litter layer, each plot was instrumented with a zero tension lysimeter constructed by cutting a $10.5 \mathrm{~cm} \times 50$ $\mathrm{cm}$ PVC pipe in half longitudinally and installing it at the soil surface. Lysimeters were filled with washed basaltic gravel $(<2.5 \mathrm{~cm}$ diameter $)$ and covered with a 0.5 -mm mesh nylon screen to exclude large debris. Throughfall captured in the lysimeters was drained to polyethylene collapsible carboys contained in opaque plastic buckets buried to the soil surface outside the experimental plots. Leachate volume was determined gravimetrically every 3-4 d using a hanging scale (Intercomp, Medina, Minnesota, USA), and a subsample from each lysimeter was collected and immediately frozen for subsequent $\mathrm{C}$ and nutrient analyses. In addition, incident canopy throughfall was collected and measured using a set of five $314-\mathrm{cm}^{2}$ funnels deployed throughout the experimental plot matrix that drained to another set of carboys, and throughfall $\mathrm{C}$ and nutrient fluxes were calculated as the differences between lysimeter and throughfall fluxes. Dissolved organic C (DOC) and total dissolved nitrogen (TDN) in all samples were determined using a high-temperature combustion total $\mathrm{C}$ and $\mathrm{N}$ analyzer (Shimadzu TOCvcpn, Kyoto, Japan), and total dissolved phosphorus (P) was determined using an autoanalyzer (OI 
Analytical, College Station, Texas, USA) following persulfate oxidation (D'Elia et al. 1977).

\section{Soil respiration}

Soil respiration was measured weekly from November 2007 to November 2008 using a vented, closed soil chamber system (LI-6400, LI-COR, Lincoln, Nebraska, USA). Each plot included one permanent PVC collar $\left(\sim 80 \mathrm{~cm}^{2}\right)$ inserted to $10-\mathrm{cm}$ depth in the soil at randomly selected positions within each of the 20 experimental and 10 control plots. For each measurement, the soil respiration chamber was placed on the collar, and $\mathrm{CO}_{2}$ flux was calculated from linear regression of increasing $\mathrm{CO}_{2}$ concentration over the 35 min following chamber equilibration. For each of the treatments (control, $-25 \%$ rainfall, and $-50 \%$ rainfall), mean $\mathrm{CO}_{2}$ efflux rates were calculated from the 10 chamber measurements obtained during individual sampling events.

\section{Soil nutrient fluxes}

Soil nutrient fluxes (to $15 \mathrm{~cm}$ ) were assessed using prefabricated ion-exchange resin capsules (Unibest, Bozeman, Montana, USA). Every 4-6 weeks, resin capsules were inserted in each plot to $10-15 \mathrm{~cm}$ by carefully creating a slit in the soil with a hand trowel, inserting the capsule, and carefully removing the blade to minimize disturbance. Resin-exchanged inorganic $\mathrm{N}$ $\left(\mathrm{NH}_{4}{ }^{+}\right.$and $\left.\mathrm{NO}_{3}{ }^{-}\right)$and $\mathrm{P}\left(\mathrm{PO}_{4}{ }^{3-}\right)$ were determined following extraction in $2 \mathrm{~mol} / \mathrm{L} \mathrm{HCl}$ and colorimeteric analysis on an autoanalyzer.

\section{Soil oxygen concentrations}

Soil $\mathrm{O}_{2}$ concentrations were assessed using a method described by Silver et al. (1999). Soil $\mathrm{O}_{2}$ chambers were constructed from $5 \times 12 \mathrm{~cm}$ PVC tubes that were capped at one end with a brass hose barb connecting a $5-\mathrm{cm}$ nylon tube closed with a stopcock. In each experimental plot, chambers were installed to $\sim 9-\mathrm{cm}$ depth in the soil and allowed to equilibrate for one week with the soil atmosphere. Soil $\mathrm{O}_{2}$ concentrations were measured weekly by extracting $50 \mathrm{~mL}$ of headspace from the chamber and flushing a specially designed $5-\mathrm{mL}$ chamber surrounding an $\mathrm{O}_{2}$ probe on a YSI 550A handheld dissolved- $\mathrm{O}_{2}$ probe (YSI, Yellow Springs, Ohio, USA). Between measurements, the probe chamber headspace was flushed with $200-300 \mathrm{~mL}$ of atmospheric air to restore instrument readings to $\sim 100 \%$ of ambient $\mathrm{O}_{2}$ concentrations.

\section{Root and soil sampling and analysis}

Total fine-root biomass $(0-10 \mathrm{~cm})$ in the plots was measured every six months using a hand soil corer $(6 \times$ $10 \mathrm{~cm})$. In the field, root core samples were hand homogenized in a 2-mm sieve; fine roots were removed, rinsed, air dried, and stored in sealed coin envelopes. In the laboratory, roots were oven dried $\left(60^{\circ} \mathrm{C}\right.$ for $\left.72 \mathrm{~h}\right)$ and weighed to determine dry mass. Surface soil samples were collected from all plots every three months using a hand soil corer $(6 \times 10 \mathrm{~cm})$. Within $48 \mathrm{~h}$ of collection, soils were returned in a cooler on ice to the laboratory at the University of Colorado and coarsely sieved $(4 \mathrm{~mm})$ to remove plant material. Subsamples of $50 \mathrm{~g}$ were removed from each soil and air dried for physical and chemical analyses. Fresh soil samples were stored at $4{ }^{\circ} \mathrm{C}$ until analysis, and incubation experiments were initiated within $72 \mathrm{~h}$ of soil sampling to avoid artifacts incurred during long-term storage.

Extractable inorganic $\mathrm{N}\left(\mathrm{NH}_{4}^{+}+\mathrm{NO}_{3}^{-}\right)$was determined in a $2 \mathrm{~mol} / \mathrm{L} \mathrm{KCl}$ solution (18-h extraction) and $\mathrm{NH}_{4}{ }^{+}$and $\mathrm{NO}_{3}{ }^{-}$in extracts were analyzed colorimetrically on an autoanalyzer. Soil microbial biomass $\mathrm{C}$ and $\mathrm{N}$ were determined using the chloroform fumigationextraction method (CFE; Brookes et al. 1985). Fumigated $(5 \mathrm{~d})$ and unfumigated samples (6 $\mathrm{g}$ dry mass; DM) were extracted with $0.5 \mathrm{~mol} / \mathrm{L} \mathrm{K}_{2} \mathrm{SO}_{4}$ for $1 \mathrm{~h}$, centrifuged for $6 \mathrm{~min}$ at high speed, and filtered. Organic $\mathrm{C}$ and total $\mathrm{N}$ in extracts was analyzed using a Shimadzu TOCvepn total organic $\mathrm{C}$ and $\mathrm{N}$ analyzer. Microbial biomass $\mathrm{C}$ was determined as the difference between extractable organic $\mathrm{C}$ in fumigated and unfumigated samples using a proportionality constant $(\mathrm{Kc})$ of 0.45 (Vance et al. 1987). Microbial biomass $\mathrm{N}$ was determined as the difference between extractable $\mathrm{N}$ in fumigated and unfumigated samples using a correction factor $(\mathrm{Kn})$ of 0.54 (Brookes et al. 1985).

\section{Effects of DOM concentration on soil respiration}

To assess the effects of DOM concentration on soil $\mathrm{CO}_{2}$ fluxes, we performed an incubation experiment in which we added varying concentrations of DOC to soil and measured initial soil $\mathrm{CO}_{2}$ fluxes. Briefly, $\sim 8$-g soil (DM) samples $(N=4$ per treatment) were placed in funnels containing Whatman number 1 filter paper (to allow drainage of excess leachate) and amended with DOM leached from mixed litter collected from the site. In $1 \mathrm{~L}$ of de-ionized water $100 \mathrm{~g}$ of litter was leached at room temperature for $24 \mathrm{~h}$, filtered to $0.45 \mu \mathrm{m}$, and the concentration of the leachate was determined using a Shimadzu TOCvcpn. The leached DOM stock was then used to produce DOC solutions with diluted concentrations ranging from $10^{0} \times$ to $10^{-1} \times$. To simulate the effects of variations in throughfall volume and DOC concentration on soil respiration, we added constant amounts of DOC (but at concentrations of either 1118, $348,176,113$, and 0.5 [i.e., de-ionized water only] $\mathrm{mg}$ $\mathrm{DOC} / \mathrm{L}$ ) to soil samples by adjusting the volume of leachate that soil samples received. To minimize the potentially confounding effects of experimental differences in soil moisture on soil respiration, all samples received a volume of leachate that was at least sufficient to bring them to their predetermined water-holding capacity (WHC). Leachate added to samples in more dilute concentrations (but delivered in higher volumes) was carefully added to the soil in the filters using a pipette, liquid was allowed to infiltrate the soil, and 
excess liquid drained freely into Ehrlenmeyer flasks. For example, samples treated with $1100 \mathrm{mg}$ DOC/L solution received $4.2 \mathrm{~mL}$ of leachate to bring them to $100 \%$ of WHC, while samples receiving $350 \mathrm{mg} \mathrm{DOC} / \mathrm{L}$ received $13.2 \mathrm{~mL}$ of leachate and were allowed to drain to $100 \%$ of their WHC. After all samples were well drained (and thus at $100 \%$ of their WHC), filters containing DOMamended soil samples were placed in glass jars equipped with septa for gas sampling and sealed, and respired $\mathrm{CO}_{2}$ in the headspace was sampled every $2 \mathrm{~h}$ for $8 \mathrm{~h}$. The $\mathrm{CO}_{2}$ samples were measured with a Shimadzu GC-14A equipped with a thermal conductivity detector.

\section{Statistical analyses}

We tested the effects of the experimental drought on repeatedly measured variables (soil moisture, DOM flux, $\mathrm{O}_{2}$ concentrations, and soil respiration) using repeatedmeasures ANOVA with time points as factors. When significant time $\times$ treatment interactions were observed, we reanalyzed data by season. In particular, we explored the effects of treatments on measured responses during the early rainy season (May-August), when the litter pool $\mathrm{C}$ is highest and significant rainfall provides a vehicle for the delivery of DOM to the soil surface, fueling high rates of some soil processes (Cleveland and Townsend 2006). In some cases, differences among dates were explored with ANOVA with date as a fixed factor. To explore the relationship between all measured variables, Pearson product-moment correlation coefficients were calculated to assess linear associations.

The relationship between added DOC concentration and initial (2-h) soil respiration rates in the laboratory incubations were analyzed using nonlinear regression. Statistical calculations were performed using SPSS version 17 for Windows (SPSS, Chicago, Illinois, USA), and in all cases, significance was determined at $P<0.05$.

\section{ReSults}

\section{Experimental manipulations}

The experimental manipulations were intended to elicit $-25 \%$ and $-50 \%$ reductions in total throughfall reaching the litter surface (hereafter referred to as $-25 \%$ and $-50 \%$ treatments). Over the course of the experiment (November 2007-November 2008), unintercepted rainfall (i.e., in a clearing adjacent to the experimental plots) at the site was $3990 \mathrm{~mm}$ (Fig. 1A). Under the canopy, control plots received $3870 \pm 350 \mathrm{~mm}$, while the experimental plots received significantly less throughfall. Twenty-five percent and 50\% exclosure plots received $2850 \pm 290 \mathrm{~mm}$ and $1740 \pm 208 \mathrm{~mm}$ of precipitation, respectively, representing $26 \%$ and $55 \%$ measured reductions in total throughfall flux (Fig. 1A) relative to the control plots.

While the experimental manipulations drove significant changes in the magnitude of throughfall reaching the litter layer as we had intended, they did not elicit significant differences in soil moisture. Overall, data
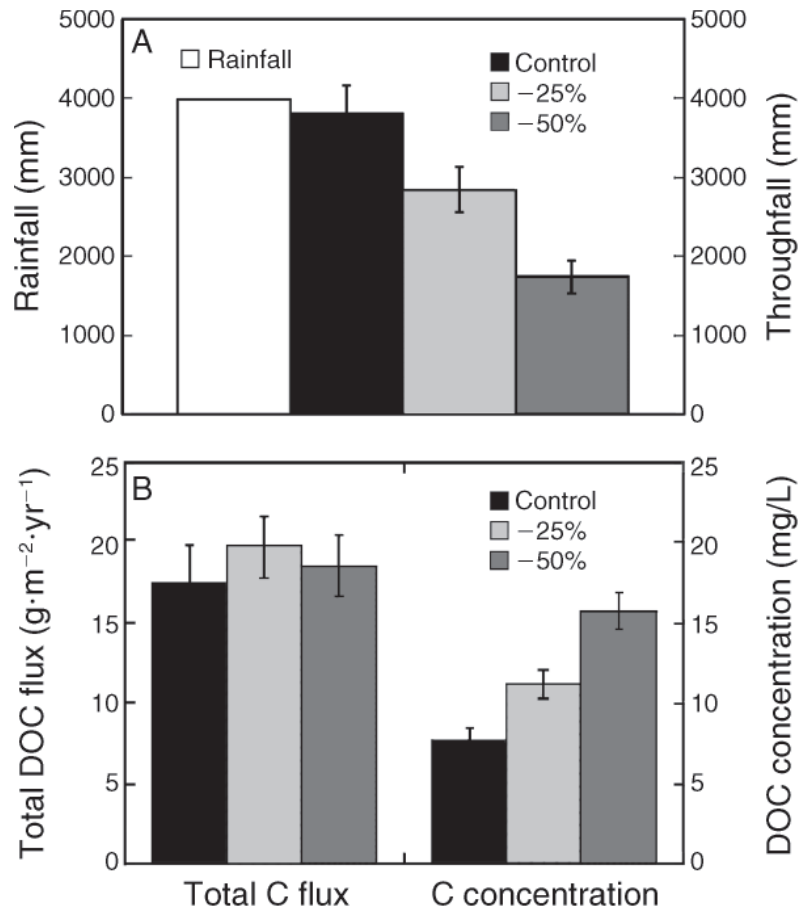

FIG. 1. (A) Annual rainfall (open histogram bar) and throughfall fluxes and (B) total annual dissolved organic carbon (DOC) fluxes and concentrations in the control and rainfall reduction $(-25 \%$ and $-50 \%)$ exclosure plots. Values are means $\pm \mathrm{SD}$. The experiment was conducted in a diverse lowland tropical rain forest on the Osa peninsula in the Golfo Dulce Forest Reserve, southwest Costa Rica.

suggested that the treatments did have subtle effects on soil moisture, but differences were not significant at any time (data not shown).

\section{DOM fluxes and concentrations}

Decreases in throughfall in the treated plots were not matched by decreases in DOM flux (Fig. 1B). Total DOM reaching the soil surface averaged $17.5 \pm 2.3 \mathrm{~g}$ $\mathrm{C} \cdot \mathrm{m}^{-2} \cdot \mathrm{yr}^{-1}, 19.7 \pm 1.9 \mathrm{~g} \mathrm{C} \cdot \mathrm{m}^{-2} \cdot \mathrm{yr}^{-1}$, and $18.5 \pm 1.9 \mathrm{~g}$ $\mathrm{C} \cdot \mathrm{m}^{-2} \cdot \mathrm{yr}^{-1}$ in the control, $-25 \%$, and $-50 \%$ plots, respectively; none of the differences were significant (Fig. 1B). However, while treatments did not drive significant differences in DOM fluxes, they did result in significant differences in the concentration of DOM reaching the soil surface. For example, over the 12month measurement period, leached DOC concentrations in the control plots averaged $7.7 \pm 0.8 \mathrm{mg} \mathrm{C} / \mathrm{L}$ vs. $11.2 \pm 0.9 \mathrm{mg} \mathrm{C} / \mathrm{L}$ in the $-25 \%$ plots and $15.8 \pm 1.2 \mathrm{mg}$ $\mathrm{C} / \mathrm{L}$ in the $-50 \%$ plots (Fig. 1B). In the early portion of the rainy season (May-August), treatment effects on leached DOC concentrations were even higher; DOC concentrations in the $-50 \%$ plots were more than three times those in the control plots.

\section{Soil respiration}

The repeated-measures ANOVA revealed highly significant time $\times$ treatment interactions for soil 

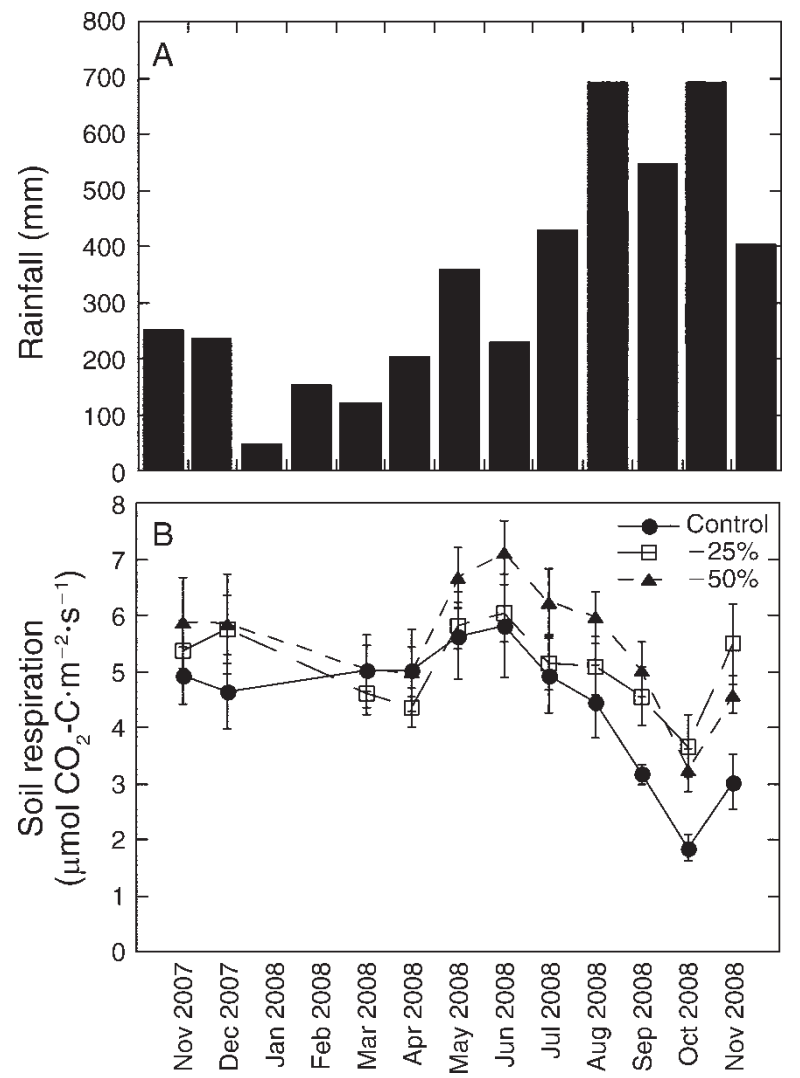

FIG. 2. (A) Monthly rainfall and (B) mean monthly surface soil $\mathrm{CO}_{2}$ fluxes (respiration) from the control and rainfall reduction $(-25 \%$ and $-50 \%)$ exclosure plots. Values represent means $\pm \mathrm{SD}$.

respiration. Consistent with previous research showing strong seasonal variation in soil respiration in this site (Cleveland and Townsend 2006), the highest rates of soil respiration were seen in the early rainy season when significant precipitation moves large fluxes of DOM to the soil surface (Fig. 2A). Thus we performed the repeated-measures ANOVA again using data only from the early rainy season (May-August 2008). This analysis showed significant treatment effects on soil $\mathrm{CO}_{2}$ fluxes, with rates of $\mathrm{CO}_{2}$ losses in the $-50 \%$ plots outpacing losses in either the $-25 \%$ or control plots (Fig. 2B). Owing largely to the early-rainy-season differences in $\mathrm{CO}_{2}$ fluxes, total estimated $\mathrm{CO}_{2}$ respired was $1293 \mathrm{~g}$ $\mathrm{C} \cdot \mathrm{m}^{-2} \cdot \mathrm{yr}^{-1}$ and $1421 \mathrm{~g} \mathrm{C} \cdot \mathrm{m}^{-2} \cdot \mathrm{yr}^{-1}$ in the $-25 \%$ and $-50 \%$ plots, respectively, representing $\sim 13 \%$ and $25 \%$ increases in total $\mathrm{CO}_{2}$ respired relative to the control plots $\left(1142 \mathrm{~g} \mathrm{C} \cdot \mathrm{m}^{-2} \cdot \mathrm{yr}^{-1}\right)$.

\section{Soil belowground biomass and biogeochemistry patterns}

Dissolved organic matter concentrations and soil respiration varied significantly between treatments, but the other measured variables did not. Root biomass across all treatments showed temporal variability over the experiment, but patterns were consistent across treatments (with no significant differences; Table 1). Neither were there significant treatment effects on soil microbial biomass $\mathrm{C}$ or $\mathrm{N}, \mathrm{O}_{2}$ concentrations, soil $\mathrm{N}$ and P fluxes, or soil total C and N (Table 1). However, when we pooled all of the data (irrespective of time or treatment), some patterns emerged. We found significant positive relationships between soil respiration, total DOC flux, DOC concentration, microbial $\mathrm{C}$, and $\mathrm{O}_{2}$, and significant negative relationships between soil respiration, throughfall flux, and soil moisture that emerged independently of the experimental manipulation (Fig. 3, Table 2).

\section{Effects of DOM concentration on soil respiration}

Our soil incubation experiment confirmed the potentially important effects of DOM concentration on soil respiration rates (Fig. 4). We found a significant relationship between DOC concentration and soil respiration rates $(P<0.001)$, and a logarithmic function provided the best fit to the data $\left(r^{2}=0.84\right)$. Across the range of DOC concentrations added to the incubation vessels, initial rates ranged from $3.8 \pm 0.62 \mu \mathrm{g} \mathrm{CO} 2^{-}$ $\mathrm{C} \cdot \mathrm{g}^{-1} \cdot \mathrm{h}^{-1}$ in samples receiving $113 \mathrm{mg} \mathrm{DOC} / \mathrm{L}$ to $5.91 \pm$ $0.18 \mu \mathrm{g} \mathrm{CO} \mathrm{CO}_{2}-\mathrm{C} \cdot \mathrm{g}^{-1} \cdot \mathrm{h}^{-1}$ in samples receiving $1118 \mathrm{mg}$ DOC/L. Respiration rates in samples receiving water only (i.e., $0.5 \mathrm{mg} \mathrm{DOC} / \mathrm{L}$ measured concentration) were

TABLE 1. Soil chemical and biological characteristics (mean \pm SD) in control and experimental plots in November 2007 and November 2008.

\begin{tabular}{|c|c|c|c|c|c|}
\hline Treatment & Soil C (\%) & Soil N (\%) & $\begin{array}{l}\text { Microbial biomass } \\
\text { C }(\mu \mathrm{g} / \mathrm{g})\end{array}$ & $\begin{array}{l}\text { Microbial biomass } \\
\mathrm{N}(\mu \mathrm{g} / \mathrm{g})\end{array}$ & $\begin{array}{c}\text { Fine-root biomass } \\
\left(\mathrm{g} / \mathrm{m}^{2}\right)\end{array}$ \\
\hline \multicolumn{6}{|c|}{ November 2007} \\
\hline $\begin{array}{l}\text { Control } \\
-25 \% \\
-50 \%\end{array}$ & $\begin{array}{l}4.75 \pm 0.42 \\
4.63 \pm 0.34 \\
4.45 \pm 0.33\end{array}$ & $\begin{array}{l}0.44 \pm 0.01 \\
0.44 \pm 0.03 \\
0.43 \pm 0.02\end{array}$ & $\begin{array}{l}899 \pm 171 \\
740 \pm 154 \\
860 \pm 153\end{array}$ & $\begin{array}{l}54.4 \pm 7.9 \\
44.7 \pm 10.1 \\
50.3 \pm 10.0\end{array}$ & $\begin{array}{l}272.9 \pm 179.7 \\
189.6 \pm 128.6 \\
270.0 \pm 155.6\end{array}$ \\
\hline \multicolumn{6}{|c|}{ November 2008} \\
\hline $\begin{array}{l}\text { Control } \\
-25 \% \\
-50 \%\end{array}$ & $\begin{array}{l}5.04 \pm 0.49 \\
5.03 \pm 0.41 \\
4.96 \pm 0.37\end{array}$ & $\begin{array}{l}0.41 \pm 0.03 \\
0.42 \pm 0.02 \\
0.41 \pm 0.01\end{array}$ & $\begin{array}{r}829 \pm 227 \\
1082 \pm 279 \\
975 \pm 220\end{array}$ & $\begin{array}{l}46.9 \pm 13.8 \\
50.7 \pm 13.6 \\
50.5 \pm 18.2\end{array}$ & $\begin{array}{l}123.0 \pm 116.2 \\
147.8 \pm 143.5 \\
160.1 \pm 110.9\end{array}$ \\
\hline
\end{tabular}

Notes: There were no significant differences in any of the measured variables at the beginning of the experiment, nor were there any significant effects of treatment $(-25 \%$ and $-50 \%$ denote rainfall reduction experiments) on the variables reported here. The experiment was conducted in a diverse lowland tropical rain forest on the Osa peninsula in the Golfo Dulce Forest Reserve, southwest Costa Rica. 

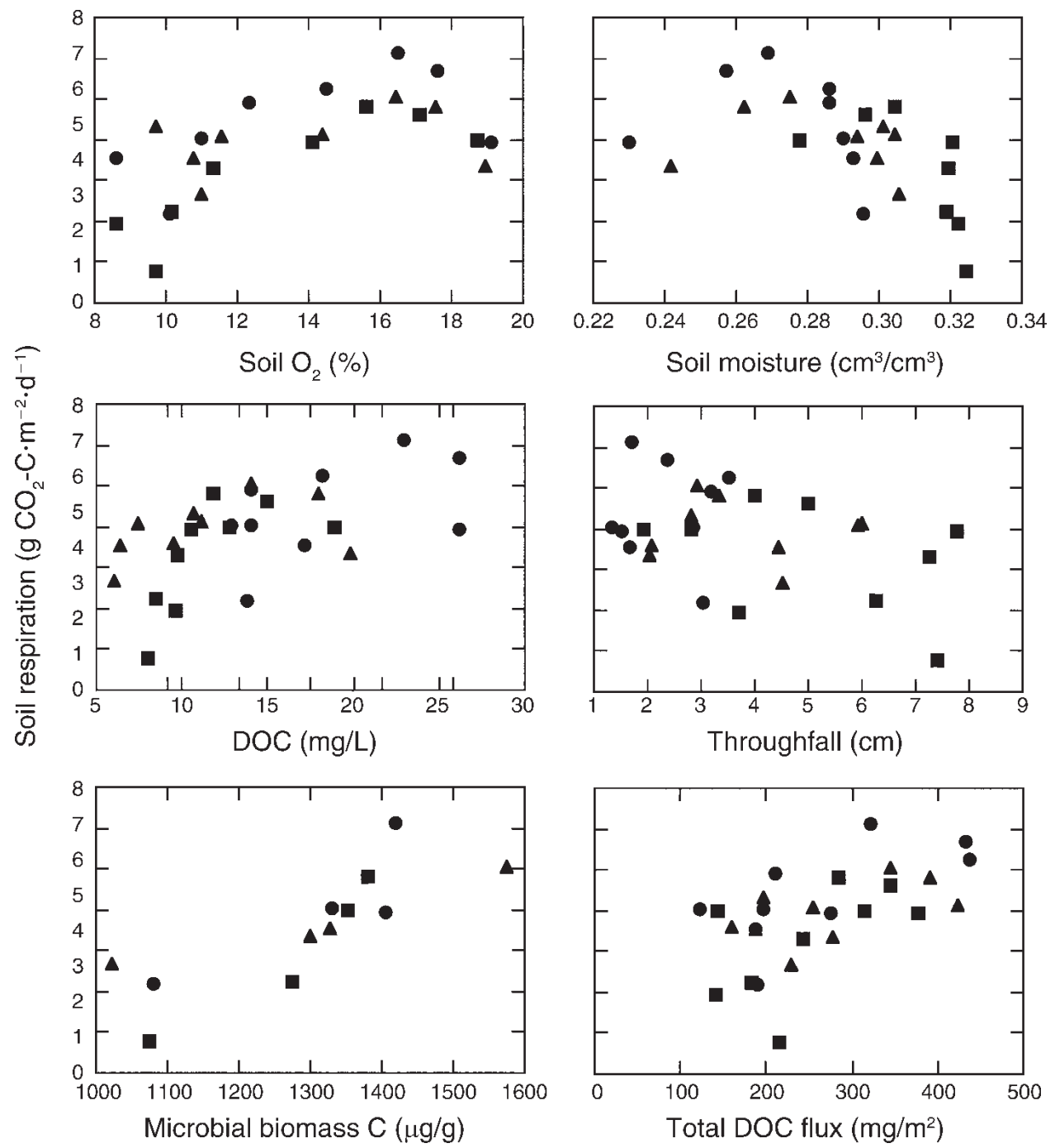

FIG. 3. Rates of soil respiration plotted as a function of six measured variables. Different symbols represent data from control plots (squares), $-25 \%$ rainfall (triangles), and $-50 \%$ rainfall (circles) throughfall manipulation plots. DOC is dissolved organic carbon.

significantly lower than rates in any of the other treatments, suggesting that the respiration responses to all concentrations of DOC were at least in part driven by the additions. In addition, a threefold variation in DOC concentration (similar to the variation in DOC concen- tration observed in the field lysimeters) corresponded with an $\sim 50 \%$ increase in soil respiration rates from samples receiving $113 \mathrm{mg} \mathrm{DOC} / \mathrm{L}$ to those receiving $348 \mathrm{mg} \mathrm{DOC} /$ $\mathrm{L}$, similar to the observed increase in in situ respiration in the $-50 \%$ plots relative to the control plots (Fig. 2).

TABLE 2. Pearson product-moment correlations between measured variables across all treatments and time points.

\begin{tabular}{|c|c|c|c|c|c|c|c|c|c|}
\hline Variable & $\begin{array}{c}\text { Soil } \\
\text { respiration }\end{array}$ & {$[\mathrm{DOC}]$} & $\begin{array}{c}\text { Total } \\
\text { DOC flux }\end{array}$ & $\begin{array}{c}\text { Soil } \\
\text { moisture }\end{array}$ & Throughfall & $\begin{array}{l}\text { Microbial } \\
\text { biomass C }\end{array}$ & $\begin{array}{c}\text { Soil } \\
\text { N flux }\end{array}$ & $\begin{array}{l}\text { Soil } \\
\text { P flux }\end{array}$ & {$\left[\mathrm{O}_{2}\right]$} \\
\hline Soil respiration & 1 & & & & & & & & \\
\hline$[\mathrm{DOC}]$ & 0.61 & 1 & & & & & & & \\
\hline Total DOC flux & 0.57 & 0.31 & 1 & & & & & & \\
\hline Soil moisture & -0.52 & -0.81 & -0.36 & 1 & & & & & \\
\hline Throughfall & -0.40 & -0.52 & 0.50 & 0.59 & 1 & & & & \\
\hline Microbial C & 0.81 & 0.53 & 0.66 & -0.51 & -0.53 & 1 & & & \\
\hline $\mathrm{N}$ flux & 0.522 & 0.02 & 0.56 & -0.01 & -0.22 & 0.42 & 1 & & \\
\hline P flux & -0.03 & 0.23 & 0.33 & -0.12 & -0.20 & -0.16 & -0.08 & 1 & \\
\hline$\left[\mathrm{O}_{2}\right]$ & 0.60 & 0.70 & 0.67 & -0.74 & -0.26 & 0.65 & 0.35 & 0.43 & 1 \\
\hline
\end{tabular}

Notes: Values in boldface are significant at $\alpha=0.05$. DOC is dissolved organic carbon. 


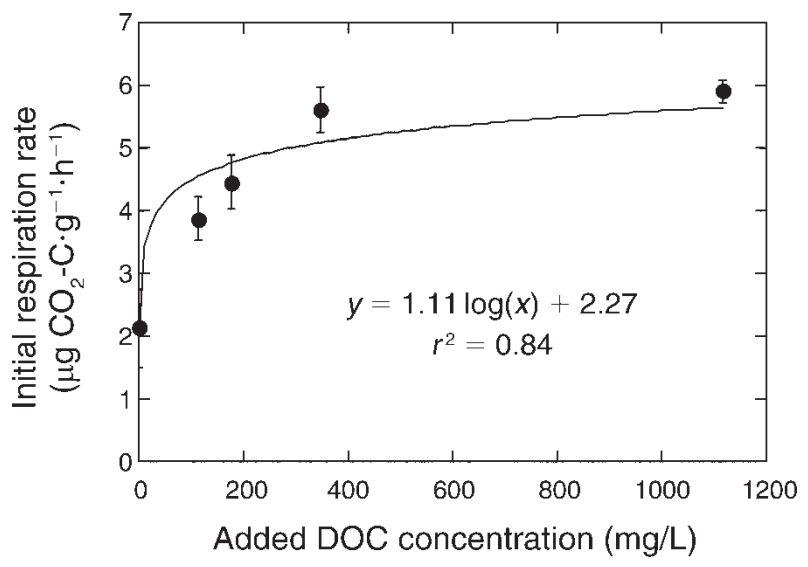

FIg. 4. Soil respiration rate responses to added dissolved organic carbon (DOC) in laboratory incubations. Values represent means $\pm \mathrm{SD}$ of initial (2-h) soil $\mathrm{CO}_{2}$ fluxes $(N=5$ per treatment). A logarithmic function is fit to the data.

\section{Discussion}

Although climate models predict changes in both temperature and precipitation for much of the humid tropics, direct manipulations of climate in tropical rain forests are rare. The few that do exist suggest a positive relationship between precipitation and ecosystem $\mathrm{C}$ fluxes. For example, dry-season irrigation on Barro Colorado Island in Panama significantly increased rates of decomposition, demonstrating that even in tropical rain forests, low soil moisture has the potential to limit process rates (Wieder and Wright 1995, Yavitt et al. 2004). Likewise, throughfall reduction in an eastern Amazonian forest reduced root growth and thus soil $\mathrm{CO}_{2}$ efflux (Cattânio et al. 2002). A subsequent, much larger rainfall exclusion experiment in Amazonia (Davidson et al. 2004, 2008, Nepstad et al. 2007) had subtle (if any) effects on belowground $\mathrm{C}$ losses, but did increase liana and tree mortality, suggesting that future drought may drive large declines in overall $\mathrm{C}$ stocks (Brando et al. 2008).

All of the above climate manipulations were conducted in the dry portions of the tropical forest rainfall spectrum (i.e., mean annual precipitation in the sites ranges between 1800 and $2600 \mathrm{~mm} / \mathrm{yr}$ ). However, $\sim 21 \%$ of lands between $17.5^{\circ} \mathrm{N}$ and $\mathrm{S}$ receive $>2500 \mathrm{~mm} / \mathrm{yr}$ (New et al. 2002), and the potential effects of drought in wetter tropical forests remain largely unknown. The general belief is that in wet tropical forests, rainfall-induced soil anoxia frequently limits decomposition and nutrient turnover (Silver et al. 1999, Schuur and Matson 2001) and thus drier conditions could enhance both soil C losses via respiration and C gains via NPP (Schuur 2003). Yet, past work in the site studied here, one that averages $\sim 5000 \mathrm{~mm} / \mathrm{yr}$ of rainfall, suggests that high precipitation may actually accelerate several key aspects of the $\mathrm{C}$ cycle.

For example, in this forest high rainfall moves substantial amounts of DOM from the canopy and litter layer into surface soils, a flux which appears to exert important controls over heterotrophic activity (Cleveland and Townsend 2006). Furthermore, in the same throughfall manipulation plots described here, experimental drought significantly reduced litter mass loss rates (Wieder et al. 2009), suggesting that drier conditions might reduce soil $\mathrm{CO}_{2}$ emissions through reductions in $\mathrm{C}$ inputs to soil. As such, we hypothesized that throughfall reduction would: (1) reduce the delivery of DOM to surface soils; and (2) therefore reduce soil respiration.

Surprisingly, in spite of the large declines in total throughfall in the $-25 \%$ and $-50 \%$ plots (Fig. 1A), total fluxes of DOM reaching the soil surface did not vary between treatments (Fig. 1B). Instead, increases in DOM concentration in the drier plots compensated for the reductions in throughfall (Fig. 1B). Thus, declines in throughfall did not appear to result in lower total DOM fluxes, but merely to increase the concentration of leached DOM reaching the soil surface. This result is in contrast to that of Wieder et al. (2009), who observed that throughfall reduction slowed litter mass loss. The DOM flux data here suggest that those lower decay rates are not the product of less DOM loss from the litter pool.

Despite the reduction in mass loss rates, and in contrast to our expectations, overall soil respiration was highest in the plots receiving the lowest throughfall inputs. As we have observed previously in this site (Cleveland and Townsend 2006), soil respiration was strongly seasonal, with the highest rates occurring in the early portion of the wet season when large litter pools and abundant rainfall combine to promote maximum fluxes of soluble DOM to decomposers at the soil surface. However, this seasonal spike in soil respiration was greatest in the $-50 \%$ plots (Fig. 2B). This increase could not be explained by changes in soil nutrients, soil microbial biomass, soil $\mathrm{O}_{2}$, fine-root biomass, or soil moisture; although some patterns appeared to emerge, we saw no significant differences in any of these variables in response to the experimental drought. However, a laboratory experiment in which we manipulated DOM concentrations provides some evidence that simple changes in the concentration of leached DOM may be at least partially responsible for the increases in soil respiration in the $-50 \%$ throughfall plots (Fig. 4).

Several studies have shown that substrate availability may limit soil respiration rates (e.g., Craine et al. 1999, Högberg et al. 2001, Wan and Luo 2003). However, to our knowledge, this experiment is among the first to show that drought-induced increases in soil respiration may be influenced by the concentration of DOM, not merely the total amount of DOM. Rates of many microbial processes (including soil respiration) increase as a function of substrate concentration (e.g., Davidson et al. 2006, Plante and Parton 2007). The laboratory incubation also showed that soil $\mathrm{CO}_{2}$ fluxes increased with increasing DOC concentrations (Fig. 4), suggesting 
that a threefold change in DOM concentration (similar to the change in concentration observed in the field experiment) could, at least in part, account for the increase in respiration in response to the experimental throughfall reductions. However, the overall increase in the amount of $\mathrm{CO}_{2}-\mathrm{C}$ lost to atmosphere from the $-50 \%$ plots was more than 10 times larger than the DOC flux measured in the lysimeters (Fig. 1B). Thus, while our data suggest that higher leached DOC concentrations could contribute to the increase in $\mathrm{CO}_{2}$ fluxes observed in the $-50 \%$ plots, the difference in magnitude between the DOM and $\mathrm{CO}_{2}$ fluxes suggests that enhanced DOM respiration efficiency under higher DOC concentrations alone does not explain the differences in soil respiration rates.

A number of possible factors could contribute to the observed increases in soil respiration with experimental drought. First, increased respiration efficiency in response to high DOM concentrations, combined with the likelihood of greater soil priming under higher DOM concentrations, may account for some of the variation. For example, multiple studies have shown that increased soil $\mathrm{C}$ losses in response to increased labile $\mathrm{C}$ availability are driven by both the decomposition of the labile $\mathrm{C}$ and by the decomposition of native soil C that was "primed" by labile C inputs (see reviews by Kuzyakov et al. 2000 and Fontaine et al. 2003). Alternatively, microscale variations in soil $\mathrm{O}_{2}$ availability (that may not be detectable using bulk soil $\mathrm{O}_{2}$ measurements) may also contribute to the increase in $\mathrm{CO}_{2}$ fluxes in response to the experimental drought. While the exact mechanisms driving the observed responses are unclear, our data suggest an intriguing possibility: in wet sites where a high proportion of litter $\mathrm{C}$ fluxes occur via leaching (Neff and Asner 2001, Cleveland et al. 2006), increases in soluble $\mathrm{C}$ concentrations during drought conditions could contribute to more rapid respiration of both incoming and extant soil organic $\mathrm{C}$, which, under normal conditions would be more prone to long-term stabilization in the soil profile (Neff and Asner 2001), and/or export to aquatic ecosystems.

Treatment-level differences in other potential drivers of soil respiration, such as soil moisture, nutrient availability, and soil $\mathrm{O}_{2}$, were not apparent, but multiple studies have shown these factors regulate tropical soil respiration (Silver et al. 1999, Schuur and Matson 2001, Cleveland and Townsend 2006). To further investigate these potential controls, we examined the relationships across the entire data set, independent of the experimental manipulation. As suggested by previous research, we saw strong positive relationships between DOC (both total flux and concentration), soil microbial biomass, and soil respiration rates (Fig. 3). Surprisingly, although nutrient, and in particular $\mathrm{P}$ availability, exerts strong control over soil respiration and other ecosystem processes in this and other P-poor tropical forest sites (Ilstedt and Singh 2005, Cleveland and Townsend 2006, Benner et al. 2007, Reed et al. 2008, Wieder et al. 2008), there was not a significant relationship between nutrient flux (as assessed with ion exchange resins) and soil $\mathrm{CO}_{2}$ fluxes. However, this lack of a significant relationship between nutrient flux and soil respiration may simply reflect the considerable variability in the nutrient flux data.

Overall, our results corroborate recent research suggesting that declines in precipitation in wet tropical forests may drive higher soil $\mathrm{CO}_{2}$ losses to the atmosphere (e.g., Phillips et al. 2009). Several studies have shown that in sites with high rainfall, maximum soil respiration rates coincide with periods of low soil moisture (presumably because high soil moisture reduces $\mathrm{O}_{2}$ diffusion), and more frequent anoxic conditions suppress both $\mathrm{CO}_{2}$ production rates (via inhibitory effects on aerobic soil respiration) and nutrient cycling. For example, in a study conducted in an old-growth forest at the La Selva Biological Station in Costa Rica, Schwendenmann et al. (2003) showed that temporal variations in soil water content explained much of the variation in soil $\mathrm{CO}_{2}$ fluxes, with high respiration rates coinciding with periods of lower soil moisture. Similarly, Schuur and Matson (2001) showed that soil $\mathrm{CO}_{2}$ fluxes declined as a function of rainfall along a precipitation gradient in the Hawaiian Islands.

Our data showed a similar pattern. When we analyzed all the data together (i.e., irrespective of time or treatment) our results indicated that while DOC concentration may regulate soil respiration rates to some extent (Table 2), so too do a number of factors related to the redox status of the soil. For example, we saw highly significant direct relationships between soil respiration and soil $\mathrm{O}_{2}$ concentration and significant negative effects of both throughfall amount and soil moisture on soil $\mathrm{CO}_{2}$ fluxes (Table 2). Because $\mathrm{O}_{2}$ and DOC concentrations were correlated (Table 2), we cannot partition the relative control of each over soil respiration rates at the landscape scale, but laboratory experiments (Fig. 4) and other studies (Schuur and Matson 2001, Schwendenmann et al. 2003) suggest that each could partially regulate $\mathrm{CO}_{2}$ fluxes. In particular, these data add to past work suggesting that high precipitation and soil moisture in tropical forests may help limit $\mathrm{C}$ fluxes to the atmosphere and imply that increased DOC and $\mathrm{O}_{2}$ concentrations under climatechange-induced drought scenarios (IPCC 2007) could provide a mechanism for increased soil $\mathrm{CO}_{2}$ emissions.

A number of climate models predict that global climate change will include both increases in temperature and decreases in rainfall throughout much of the humid tropics (IPCC 2007), and previous research suggests such changes could have strong negative effects on plant growth and hence C uptake (Clark et al. 2003, Nepstad et al. 2007). Our results are disconcerting in that they suggest that drought in wet tropical rain forests could also accelerate soil C losses from soil to the atmosphere. However, while the goal of our experiment 

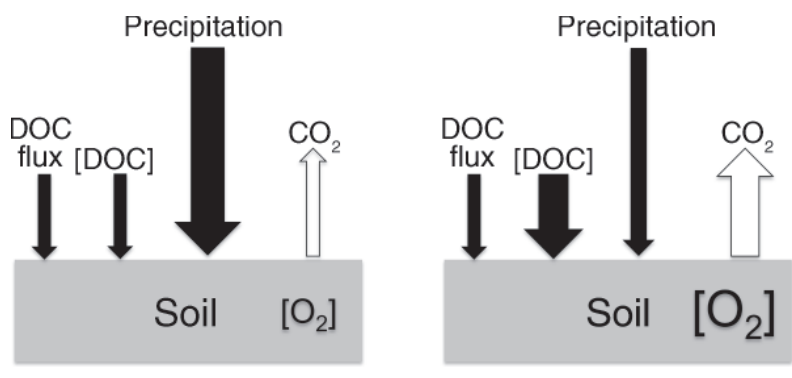

FIG. 5. Conceptual model illustrating the potential effects of declines in precipitation on soil $\mathrm{O}_{2}$ concentration $\left(\left[\mathrm{O}_{2}\right]\right)$, leached dissolved organic carbon concentration ([DOC]), total DOC (DOC flux), and soil $\mathrm{CO}_{2}$ flux. The sizes of the arrows or lettering reflect relative differences in fluxes or concentrations in response to the experimental drought. Declining precipitation may not directly affect the total amount of leached DOC moving from the litter to the soil surface but could increase $\mathrm{CO}_{2}$ efflux by eliciting increases in both soil $\left[\mathrm{O}_{2}\right]$ and leached [DOC].

was to isolate the possible effects of drought on soil respiration, climate change will undoubtedly affect multiple other components of the tropical $\mathrm{C}$ cycle (e.g., plant productivity) in ways that could overwhelm the responses we observed. Ultimately, the net $\mathrm{C}$ balance of any forest will depend on a complex set of responses that include not only the physiological responses of above- and belowground communities, but also any climate-driven shifts in the composition of those communities (e.g., Wright 2005). However, our data suggest another possible mechanism (i.e., increases in leached DOM concentrations) that could contribute to increased C losses from soils under lower rainfall (Fig. 5) and add to a growing body of evidence raising concern that projected climate changes in tropical regions could reduce ecosystem $\mathrm{C}$ storage by driving higher $\mathrm{CO}_{2}$ losses to the atmosphere.

\section{ACKNOWLEDGMENTS}

We thank W. Combronero-Castro for his invaluable assistance with fieldwork in Costa Rica. We thank H. Michaud and M. Jimenez of the Drake Bay Wilderness Camp for providing field access and logistical support, and we also thank F. Campos Rivera, the Organización para Estudios Tropicales (OET), and the Ministerio de Ambiente y Energia (MINAE) for assisting with research permits and logistics in Costa Rica. $P$. Taylor provided valuable discussions and insight during the data analysis and interpretation, and J. Leff, R. Kimmel, M. Martin, and T. Dietzler assisted with the laboratory and data analyses. We are grateful to W. Silver for providing valuable suggestions during the planning and implementation phases of the experiment and to E. Davidson and one anonymous reviewer for valuable comments and suggestions on the submitted manuscript. National Science Foundation Grants DEB 0515744 and DEB 0852916 supported this work.

\section{Literature Cited}

Benner, J. W., S. Conroy, C. K. Lunch, N. Toyoda, and P. M. Vitousek. 2007. Phosphorus fertilization increases the abundance and nitrogenase activity of the cyanolichen Pseudocyphellaria crocata in Hawaiian montane forests. Biotropica 39: 400-405.
Berrange, J. P., and R. S. Thorpe. 1988. The geology, geochemistry, and emplacement of the Cretaceous-Tertiary ophiolitic Nicoya Complex of the Osa Peninsula, southern Costa Rica. Tectonophysics 147:193-220.

Brando, P. M., D. C. Nepstad, E. A. Davidson, S. E. Trumbore, D. Ray, and P. Camargo. 2008. Drought effects on litterfall, wood production and belowground carbon cycling in an Amazon forest: results of a throughfall reduction experiment. Philosophical Transactions of the Royal Society B 363:1839-1848.

Brookes, P. C., A. Landman, G. Pruden, and D. S. Jenkinson. 1985. Chloroform fumigation and the release of soil nitrogen: a rapid direct extraction method to measure microbial biomass nitrogen in soil. Soil Biology and Biochemistry 17: 837-842.

Cattânio, J. H., E. A. Davidson, D. C. Nepstad, L. V. Verchot, and I. L. Ackerman. 2002. Unexpected results of a pilot throughfall exclusion experiment on soil emissions of $\mathrm{CO}_{2}$, $\mathrm{CH}_{4}, \mathrm{~N}_{2} \mathrm{O}$, and $\mathrm{NO}$ in eastern Amazonia. Biology and Fertility of Soils 36:102-108.

Clark, D. A., S. C. Piper, C. D. Keeling, and D. B. Clark. 2003. Tropical rain forest tree growth and atmospheric carbon dynamics linked to interannual temperature variation during 1984-2000. Proceedings of the National Academy of Sciences USA 100:5852-5857.

Cleveland, C. C., S. C. Reed, and A. R. Townsend. 2006. Nutrient regulation of organic matter decomposition in a tropical rain forest. Ecology 87:492-503.

Cleveland, C. C., and A. R. Townsend. 2006. Nutrient additions to a tropical rain forest drive substantial soil carbon dioxide losses to the atmosphere. Proceedings of the National Academy of Sciences USA 103:10316-10321.

Cox, P. M., R. A. Betts, M. Collins, P. P. Harris, C. Huntingford, and C. D. Jones. 2004. Amazonian forest dieback under climate-carbon cycle projections for the 21st century. Theoretical and Applied Climatology 78:137-156.

Craine, J. M., D. A. Wedin, and F. S. Chapin, III. 1999. Predominance of ecophysiological controls on $\mathrm{CO}_{2}$ flux in a Minnesota grassland. Plant and Soil 207:77-86.

Davidson, E. A., F. Y. Ishida, and D. C. Nepstad. 2004. Effects of an experimental drought on soil emissions of carbon dioxide, methane, nitrous oxide, and nitric oxide in a moist tropical forest. Global Change Biology 10:718-730.

Davidson, E. A., and I. A. Janssens. 2006. Temperature sensitivity of soil carbon decomposition and feedbacks to climate change. Nature 440:165-173.

Davidson, E. A., I. A. Janssens, and Y. Luo. 2006. On the variability of respiration in terrestrial ecosystems: moving beyond $\mathrm{Q}_{10}$. Global Change Biology 12:154-164.

Davidson, E. A., D. C. Nepstad, F. Y. Ishida, and P. M. Brando. 2008. Effects of an experimental drought and recovery on soil emissions of carbon dioxide, methane, nitrous oxide, and nitric oxide in a moist tropical forest. Global Change Biology 14:2582-2590.

D'Elia, C. F., P. A. Steudler, and N. Corwin. 1977. Determination of total nitrogen in aqueous samples using persulfate digestion. Limnology and Oceanography 22:760764.

Fontaine, S., A. Mariotti, and L. Abbadie. 2003. The priming effect of organic matter: a question of microbial competition. Soil Biology and Biochemistry 35:837-843.

Forster, P., et al. 2007. Changes in atmospheric constituents and in radiative forcing. Pages 129-234 in S. Solomon, D. Qin, M. Manning, Z. Chen, M. Marquis, K. Averyt, M. Tignor, and H. Miller, editors. Climate change 2007: the physical science basis. Contribution of Working Group 1 to the Fourth Assessment Report of the Intergovernmental Panel on Climate Change. Cambridge University Press, Cambridge, UK.

Grace, J., Y. Malhi, N. Higuchi, and P. Meir. 2001. Productivity of tropical forests. Pages 401-428 in H. A. 
Mooney, J. Roy, and B. Saugier, editors. Terrestrial global productivity. Academic Press, London, UK.

Högberg, P., et al. 2001. Large-scale forest girdling shows that photosynthesis drives soil respiration. Nature 411:789-792.

Ilstedt, U., and S. Singh. 2005. Nitrogen and phosphorus limitations of microbial respiration in a tropical phosphorusfixing acrisol (ultisol) compared with organic compost. Soil Biology and Biochemistry 37:1407-1410.

IPCC [Intergovernmental Panel on Climate Change]. 2007. Climate change 2007: the physical science basis, summary for policymakers. Contribution of Working Group 1 to the Fourth Assessment Report of the Intergovernmental Panel on Climate Change. Cambridge University Press, Cambridge, UK.

Jobbagy, E. G., and R. B. Jackson. 2000. The vertical distribution of soil organic carbon and its relation to climate and vegetation. Ecological Applications 10:423-436.

Kuzyakov, Y., J. K. Friedel, and K. Stahr. 2000. Review of mechanisms and quantification of priming effects. Soil Biology and Biochemistry 32:1485-1498.

Malhi, Y., J. Roberts, R. Betts, T. Killeen, W. Li, and C. Nobre. 2008. Climate change, deforestation, and the fate of the Amazon. Science 319:169-172.

Neelin, J. D., M. Munnich, H. Su, J. E. Meyerson, and C. E. Holloway. 2006. Tropical drying trends in global warming models and observations. Proceedings of the National Academy of Sciences USA 103:6110-6115.

Neff, J. C., and G. P. Asner. 2001. Dissolved organic carbon in terrestrial ecosystems: synthesis and a model. Ecosystems 4: $29-48$.

Nepstad, D. C., I. M. Tohver, D. Ray, P. Moutinho, and G. Cardinot. 2007. Mortality of large trees and lianas following experimental drought in an Amazon forest. Ecology 88:22592269.

New, M., D. Lister, M. Hulme, and I. Makin. 2002. A highresolution data set of surface climate over global land areas. Climate Research 21:1-25.

Ngao, J., B. Longdoz, A. Granier, and D. Epron. 2007. Estimation of autotrophic and heterotrophic components of soil respiration by trenching is sensitive to corrections for root decomposition and changes in soil water content. Plant and Soil 301:99-110.

Phillips, O. L., et al. 1998. Changes in the carbon balance of tropical forests: evidence from long-term plots. Science 282: 439-442.

Phillips, O. L., et al. 2009. Drought sensitivity of the Amazon rainforest. Science 323:1344-1347.

Plante, A. F., and W. J. Parton. 2007. The dynamics of soil organic matter and nutrient cycling. Pages 433-467 in E. Paul, editor. Soil microbiology, ecology and biochemistry. Academic Press, Oxford, UK.

Raich, J. W., and W. H. Schlesinger. 1992. The global carbon dioxide flux in soil respiration and its relationships to vegetation and climate. Tellus 44B:81-99.

Reed, S. C., C. C. Cleveland, and A. R. Townsend. 2008. Tree species control rates of free-living nitrogen fixation in a tropical rain forest. Ecology 89:2924-2934.

Rustad, L. E., T. G. Huntington, and R. D. Boone. 2000. Controls on soil respiration: implications for climate change. Biogeochemistry 48:1-6.
Schlesinger, W. H. 1997. Biogeochemistry: an analysis of global change. Academic Press, San Diego, California, USA.

Schuur, E. A. G. 2001. The effect of water on decomposition dynamics in mesic to wet Hawaiian montane forests. Ecosystems 4:259-273.

Schuur, E. A. G. 2003. Productivity and global climate revisited: the sensitivity of tropical forest growth to precipitation. Ecology 84:1165-1170.

Schuur, E. A. G., and P. A. Matson. 2001. Net primary productivity and nutrient cycling across a mesic to wet precipitation gradient in Hawaiian montane forest. Oecologia 128:431-442.

Schwendenmann, L., E. Veldkamp, T. Brenes, J. J. O'Brien, and J. Mackensen. 2003. Spatial and temporal variation in soil $\mathrm{CO}_{2}$ efflux in an old-growth neotropical rain forest, La Selva, Costa Rica. Biogeochemistry 64:111-128.

Silver, W. H., A. E. Lugo, and M. Keller. 1999. Soil oxygen availability and biogeochemistry along rainfall and topographic gradients in upland wet tropical forest soils. Biogeochemistry 44:301-328.

Sotta, E. D., E. Veldkamp, L. Schwendenmann, B. R. Guimarães, R. K. Paixão, M. D. L. P. Ruivo, A. C. L. Da Costa, and P. Meir. 2007. Effects of an induced drought on soil carbon dioxide $\left(\mathrm{CO}_{2}\right)$ efflux and soil $\mathrm{CO}_{2}$ production in an Eastern Amazonian rainforest, Brazil. Global Change Biology 13:2218-2229.

Tarnocai, C., J. G. Canadell, E. A. G. Schuur, P. Kuhry, G. Mazhitova, and S. Zimov. 2009. Soil organic carbon pools in the northern circumpolar permafrost region. Global Biogeochemical Cycles 23:GB2023.

Townsend, A. R., P. M. Vitousek, and E. A. Holland. 1992. Tropical soils could dominate the short-term carbon cycle feedbacks to increased global temperatures. Climatic Change 22:293-303.

Trumbore, S. E. 1997. Potential responses of soil organic carbon to global environmental change. Proceedings of the National Academy of Sciences USA 94:8284-8291.

Vance, E. D., P. C. Brookes, and D. S. Jenkinson. 1987. An extraction method for measuring soil microbial biomass C. Soil Biology and Biochemistry 19:703-707.

Wan, S., and Y. Luo. 2003. Substrate regulation of soil respiration in a tallgrass prairie: results of a clipping and shading experiment. Global Biogeochemical Cycles 17:1054.

Wieder, R. K., and S. J. Wright. 1995. Tropical forest litter dynamics and dry season irrigation on Barro Colorado Island, Panama. Ecology 76:1971-1979.

Wieder, W. R., C. C. Cleveland, and A. R. Townsend. 2008. Tropical tree species composition affects the oxidation of dissolved organic matter from litter. Biogeochemistry 88: 127-138.

Wieder, W. R., C. C. Cleveland, and A. R. Townsend. 2009. Controls over leaf litter decomposition in wet tropical forests. Ecology 90:3333-3341.

Wright, S. J. 2005. Tropical forests in a changing environment. Trends in Ecology and Evolution 20:553-560.

Yavitt, J. B., S. J. Wright, and R. K. Wieder. 2004. Seasonal drought and dry-season irrigation influence leaf-litter nutrients and soil enzymes in a moist, lowland forest in Panama. Austral Ecology 29:177-188. 